\title{
Angiolipoma: A Unique Cause of Carpal Tunnel Syndrome
}

\author{
Yi Deng ${ }^{a, b}$ Sindy Vrancic ${ }^{a} \quad$ Adrienne Morey ${ }^{b, c}$ \\ aDepartment of Orthopaedic Surgery, Canberra Hospital, Canberra, ACT, Australia; ${ }^{b}$ Medical \\ School, Australian National University, Canberra, ACT, Australia; 'Australian Capital Territory \\ Pathology, Canberra Hospital, Canberra, ACT, Australia
}

\section{Keywords}

Carpal tunnel syndrome $\cdot$ Angiolipoma $\cdot$ Tumour

\begin{abstract}
Carpal tunnel syndrome is one of the most common conditions affecting the hand. The majority of cases are idiopathic, with tumours causing less than $3 \%$ of cases. We present a unique case of an angiolipoma overlying the carpal tunnel as a cause of median nerve compression. A 54-year-old female presented with signs and symptoms consistent with carpal tunnel syndrome associated with an enlarging lump overlying the carpal tunnel on the palmar surface of her hand. Nerve conduction studies confirmed median neuropathy. The case was successfully treated by surgical excision of the tumour and open carpal tunnel release. Histopathology confirmed the presence of an angiolipoma. The patient had complete resolution of symptoms at the final 6-week follow-up. This case highlights the importance of considering tumours in the differential diagnosis of carpal tunnel syndrome.
\end{abstract}

\section{Introduction}

Classic carpal tunnel syndrome (CTS) occurs most often in females of mean age around 50 years [1]. It is caused by compression of the median nerve at the wrist as it passes through the space-limited, osteofibrous canal, or carpal tunnel containing the wrist bones, transverse carpal ligament, median nerve, and digital flexor tendons. This common entrapment neuropathy is estimated to affect one in 10 people during their lifetime [2]. Apart from female sex and age, risk factors include obesity, rheumatoid arthritis, lupus, hypothyroidism, overuse injury, and pregnancy $[1,3]$. Patients usually present with pain, tingling, burning, or numbness over the median nerve distribution in the hand which includes the palmar aspect of the first, second, third, and radial half of the fourth digits. Symptoms are often worse at night, and sometimes can be relieved by shaking of the affected limb [4]. Examination findings can reveal paraesthesia in the distribution of the median nerve with diminished two-point discrimination. Provocative 
tests such as Tinel's sign and Phalen's manoeuvre can suggest the diagnosis [4]. In severe cases, patients have weakness and wasting of the thenar muscles [4]. The diagnosis is usually clinical; however, nerve conduction studies and imaging can help when the diagnosis is uncertain [5].

Compression of the median nerve causes damage by compromising the intracarpal bloodflow causing ischaemia to the endoneural capillary system and demyelination [6, 7]. Compression of the median nerve from a tumour is very rare, with less than $3 \%$ of cases of carpal tunnel syndrome due to masses arising from or around the median nerve [8]. We present a unique case report of an angiolipoma causing compression of the median nerve resulting in carpal tunnel syndrome.

\section{Patient Information}

A 54-year-old right-hand dominant female presented to the outpatient orthopaedic clinic with a 4-year history of worsening paraesthesia and burning pain in both hands. This was associated with a painful lump on the palmar aspect of her left hand, which became increasingly noticeable over the final 3-4 months prior to surgery. At the time of review, the symptoms were worse on the left side. The pain followed the distribution of the median nerve and was worse at night and with activities such as driving. She noticed weakness in her left hand and would often drop objects. Shaking her hands and wearing gloves in winter helped relieve the symptoms. Her risk factors include obesity, type 2 diabetes mellitus, hypothyroidism, and previous manual work as a massage therapist. She also had a previous anterior cervical spine stabilization procedure but denied any postoperative neurological dysfunction. Other past medical history included ischaemic heart disease, and she was under investigation for systemic lupus erythematous. She was anaphylactic to cephalosporins and latex and had various other medication allergies. Her medications included metoprolol, azathioprine, thyroxine, aspirin, ranitidine, pregabalin, and insulin. Incidentally, she also had a concurrent left shoulder adhesive capsulitis.

\section{Clinical Findings}

On examination, she had evidence of muscle wasting on the thenar eminences. She had a $15 \times 10 \mathrm{~mm}$ soft lump on the palmar surface of her left hand, just distal to the distal wrist crease, overlying the course of the median nerve. It was tender to palpation, mobile and had a well-defined margin. She had paraesthesia over the first 3 and a half digits on the palmar surface in the distribution of the median nerve. She had grade 4 power in the abductor pollicis brevis muscle. Provocative tests including Tinel's and Phalen's manoeuvres were positive.

\section{Investigations}

Nerve conduction studies demonstrated bilateral median nerve lesions at the level of the wrist, of moderate severity on the right side, and mild severity on the left side.

\section{Treatment}

Initial nonoperative treatment included splinting and taping the wrist at night to provide symptoms, which was effective in the initial stages. Cortisone injections also provided temporary relief for a number of months.

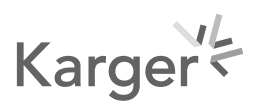


Fig. 1. Low-power haematoxylin and eosin stained section $(\times 40)$ showing a loculated fatty lesion containing numerous small proliferating $\mathrm{V}$ and focal H. V, vessels, $H$, haemorrhage.

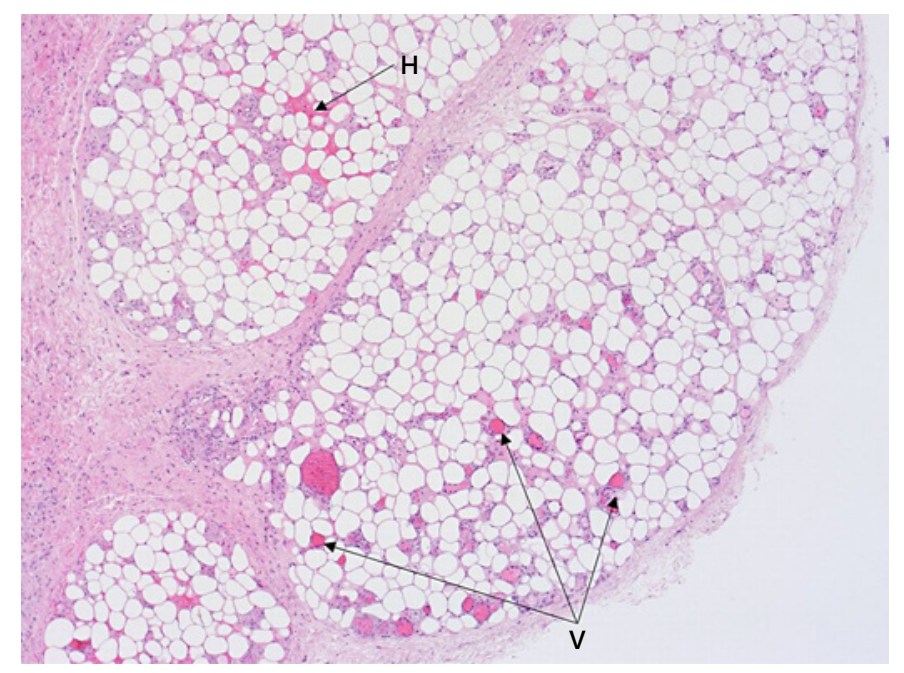

An open left carpal tunnel release and excision of lump were performed under general anaesthesia. A $15 \times 10$-mm soft white lump was identified on the radial aspect overlying the transverse carpal ligament and was excised. Then, we proceeded to release the transverse carpal ligament. The median nerve appeared visibly inflamed, and there was a blush following the release of the ligament. The skin was closed with nylon sutures, and dressings were applied.

\section{Histopathology}

Macroscopically, the mass was a piece of cream tissue, measuring $15 \times 10 \times 4 \mathrm{~mm}$ in size. Microscopically, the soft tissue mass consisted of loculated mature adipose tissue, divided by fibrous septae, with small collections of blood vessels containing fibrin thrombi at the periphery of the fat locules. These features are consistent with an angiolipoma. No lipoblasts or other atypical features were present (Fig. 1, 2).

\section{Follow-Up}

Despite a slight delay in wound healing, the patient had a good outcome. At 2 weeks, 6 weeks, and 5 months postoperatively, the patient had complete resolution of pain and paraesthesia in her hand. There were no signs of local recurrence of the lump at the time of final review, 5 months after surgery.

\section{Discussion}

A lipoma is a benign tumour of adipose tissue. Lipomas can occur anywhere on the body where there is adipose tissue. Every lipoma has vascularity; however, when the vascularity exceeds that of a normal lipoma, the lesion is termed an angiolipoma [9], particularly if there is thrombosis noted within the blood vessels [10]. Angiolipomas are benign subcutaneous lesions which are usually tender [11]. Treatment is usually nonoperative symptom management; however, surgical resection is curative for single lesions [11]. The treatment for multiple lesions is difficult, but liposuction can be a potential method of management [12]. 
Case Reports in Orthopedic Research

\begin{tabular}{l|l}
\hline Case Rep Orthop Res 2021;4:24-28 \\
\hline DOI: 10.1159/000511968 & $\begin{array}{l}\text { ○ 2021 The Author(s). Published by S. Karger AG, Basel } \\
\text { www.karger.com/cio }\end{array}$ \\
\hline
\end{tabular}

Deng et al.: Angiolipoma Causing Carpal Tunnel Syndrome

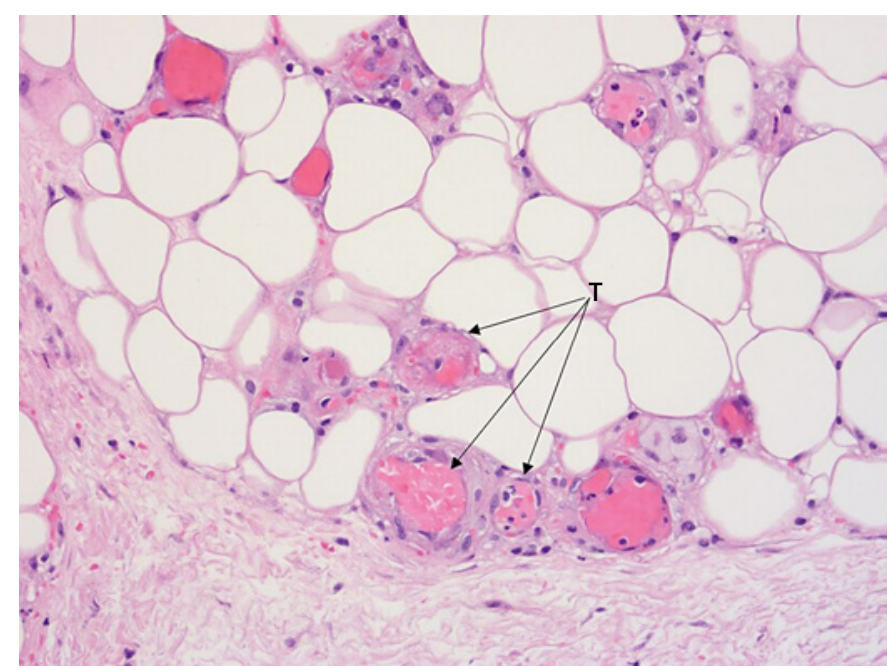

Fig. 2. High-power haematoxylin and eosin stained section $(\times 400)$ demonstrating typical fibrin $\mathrm{T}$ in small proliferating vessels at the periphery of fat locules. T, thrombi.

Occasionally, tumours can cause carpal tunnel syndrome, the majority being benign lesions. These include lipomas, vascular tumours, Dupuytren's contractures, giant-cell tumours, and nerve sheath tumours $[8,13]$. Usually, these masses are palpable and cause pain although are often slow growing. However, when this is not the case, it can be difficult to diagnose. A case of a metaplastic synovial cyst in the carpal tunnel highlights this as they did not perform ultrasound or MRI preoperatively to aid their diagnosis [14]. Lipomas have also been reported to cause other forms of entrapment neuropathy in both upper and lower limbs [15]. Two previous reports have described lipomas causing carpal tunnel syndrome [16-18]. Angiolipomas have been known to cause nerve compression in the spine [19]. However, there have been no previous cases reported of angiolipoma causing carpal tunnel syndrome or other entrapment neuropathies in peripheral nerves.

\section{Conclusion}

Carpal tunnel syndrome can be caused by tumours in rare cases. In this case report, we describe a unique case of an angiolipoma causing carpal tunnel syndrome. This case highlights the importance of considering tumours in the differential diagnosis during the assessment and management of carpal tunnel syndrome and of submitting atypical tissue encountered during carpal tunnel release for histopathological examination.

\section{Statement of Ethics and Consent}

The patient has provided written informed consent for the case to be used for publication purposes. The patient's identity is concealed throughout this paper. Ethical approval was not required and therefore not obtained as this was not a clinical trial.

\section{Conflict of Interest Statement}

The authors have no conflicts of interest to declare.

\section{Karger'}




\section{Case Reports in Orthopedic Research}

\begin{tabular}{l|l}
\hline Case Rep Orthop Res 2021:4:24-28 \\
\hline DOI: 10.1159/000511968 & $\begin{array}{l}\text { @ 2021 The Author(s). Published by S. Karger AG, Basel } \\
\text { www.karger.com/cio }\end{array}$ \\
\hline
\end{tabular}

Deng et al.: Angiolipoma Causing Carpal Tunnel Syndrome

\section{Funding Sources}

The authors did not receive any funding for this case report.

\section{Author Contributions}

Dr. Yi Deng, Dr. Sindy Vrancic, and A/Prof Adrienne Morey all had substantial contributions to the conception of the work, acquisition, and interpretation of the data for this report, drafting the manuscript, approving the final version to be published, and we all agree to be accountable for all aspects of the work.

\section{References}

1 Padua L, Coraci D, Erra C, Pazzaglia C, Paolasso I, Loreti C, et al. Carpal tunnel syndrome: clinical features, diagnosis, and management. Lancet Neurol. 2016;15(12):1273-84.

2 Practice Parameter for Carpal Tunnel Syndrome (Summary Statement). Report of the quality standards subcommittee of the American Academy of Neurology. Neurology. 1993;43(11):2406-9.

3 Burt S, Crombie K, Jin Y, Wurzelbacher S, Ramsey J, Deddens J. Workplace and individual risk factors for carpal tunnel syndrome. Occup Environ Med. 2011;68(12):928-33.

4 Katz JN, Simmons BP. Clinical practice. Carpal tunnel syndrome. N Engl J Med. 2002;346(23):1807-12.

5 Calandruccio JH, Thompson NB. Carpal tunnel syndrome: making evidence-based treatment decisions. Orthop Clin North Am. 2018;49(2):223-9.

6 Dawson DM. Entrapment neuropathies of the upper extremities. N Engl J Med. 1993;329(27):2013-8.

7 Ibrahim I, Khan WS, Goddard N, Smitham P. Carpal tunnel syndrome: a review of the recent literature. Open Orthop J. 2012;6:69-76.

8 Dailiana ZH, Bougioukli S, Varitimidis S, Kontogeorgakos V, Togia E, Vlychou M, et al. Tumors and tumor-like lesions mimicking carpal tunnel syndrome. Arch Orthop Trauma Surg. 2014;134(1):139-44.

9 Bradley RL, Klein MM. Angiolipoma. Am J Surg. 1964;108:887-8.

10 Bolognia J, Jorizo J, Schaffer J. Dermatology. 3rd ed. Edinburgh: Elsevier/Saunders; 2012.

11 Goldstein BGA. Overview of benign lesions of the skin: UpToDate; 2018 [cited 2018 Dec 17]. Available from: https://www.uptodate.com/contents/overview-of-benign-lesions-of-the-skin.

12 Kanter WR, Wolfort FG. Multiple familial angiolipomatosis: treatment of liposuction. Ann Plast Surg. 1988; 20(3):277-9.

13 Martinez-Villen G, Badiola J, Alvarez-Alegret R, Mayayo E. Nerve compression syndromes of the hand and forearm associated with tumours of non-neural origin and tumour-like lesions. J Plast Reconstr Aesthet Surg. 2014;67(6):828-36.

14 Karaytug K, Kapicioglu M, Can N, Hurmeydan OM. Unprecedented recurrence of carpal tunnel syndrome by metaplastic synovial cyst in the carpal tunnel. Acta Orthop Traumatol Turc. 2019;53(3):230-2.

15 Flores LP, Carneiro JZ. Peripheral nerve compression secondary to adjacent lipomas. Surg Neurol. 2007;67(3): $258-62$

16 Unal M, Demirayak E, Acar B, Kose O. Simultaneous median and ulnar compression neuropathy secondary to a giant palmar lipoma: a case report and review of the literature. Cureus. 2018;10(2):e2198.

17 Bagatur AE, Yalcinkaya M. Unilateral carpal tunnel syndrome caused by an occult palmar lipoma. Orthopedics. 2009;32(10).

18 Sbai MA, Benzarti S, Msek H, Boussen M, Khorbi A. Carpal tunnel syndrome caused by lipoma: a case report. Pan Afr Med J. 2015;22:51.

19 Andaluz N, Balko G, Bui H, Zuccarello M. Angiolipomas of the central nervous system. J Neurooncol. 2000; 49(3):219-30. 